\title{
Performance Evaluation of Ground Source Heat Pump Using Direct Expansion Method
}

\author{
Shuhei Ishiguro ${ }^{1)}$, Daisuke Tanaka ${ }^{2)}$, Shumpei Funatani ${ }^{1)}$, Koichi Ichimiya $^{1)}$, and Tetsuaki Takeda ${ }^{1)}$ \\ 1) Graduate School of Engineering, Dept. of Mechanical Engineering, Univ. of Yamanashi \\ 2) Graduate School of Medicine and Engineering, Univ. of Yamanashi \\ JAPAN \\ E-mail: sishiguro@yamanashi.ac.jp
}

\section{ABSTRACT}

This paper describes the experimental results and the performance of ground source heat pump using the direct expansion method. Ground source has potential energy, which does not come from the earth center, but from the sun, at local places. This kind of energy is clean and does not affect the environment. The underground temperatures are more stable than air temperature. The temperature beneath the about $10 \mathrm{~m}$ from the surface maintains a nearly constant temperature about $15-20^{\circ} \mathrm{C}$. Ground Source Heat Pump (GSHP) absorbs energy from the earth by applying this constant temperature. Authors paid attention to shallower depth than $100 \mathrm{~m}$ under the ground surface. In order to obtain the basic data, authors tried to experiment on GSHP based on direct expansion. In this experiment, performance evaluation was carried out during 48 hours operation. The performance of the ground sources heat pump system was evaluated by coefficient of performance (COP), which is determined by the ratio of heat exchange rate to consumption power of the compressor. The COP approached to 12.3 in cooling mode and 4.2 in heating mode. Totally, COP of GSHP with direct expansion method is higher than that in airsource type heat exchanger or indirect heat exchange method. In addition, long term test operations have to be considered for practical application in the near future.

\section{INTRODUCTION}

Energy problem is serious in the world. Recently, it is said that energy should be produced locally and be consumed locally. Solar energy, wind energy, biomass energy and so on, these kind of energies are popular as sustainable energies [1]. In addition, geothermal energy is useful for massive energy, but boreholes should be drilled to deep thermal sources, several hundreds or thousands meters underground surface. The location is restricted near volcanos. On the other hand, ground source has potential energy which comes from the sun and is attractive as a renewable natural energy source. This kind of energy is clean and does not affect the environment. The location is not so restricted. The location is not so restricted. Ground source energy is able to get comparatively easily near our area. In the ground source heat pump system (GSHP), two kinds of systems are applied, namely, an indirect method and a direct expansion method [2-3]. In the direct expansion method, refrigerant transfers thermal energy through primary loop without mediation. Therefore, it is expected that thermal energy is transferred effectively and performance is promoted. In the present experiment, authors focused on the shallower depth than $100 \mathrm{~m}$ from the ground surface and getting the basic data of GSHP based on a direct expansion method. In this experiment, performance evaluation was carried out during 48 hours operation.

\section{EXPERIMENTAL APPARATUS}

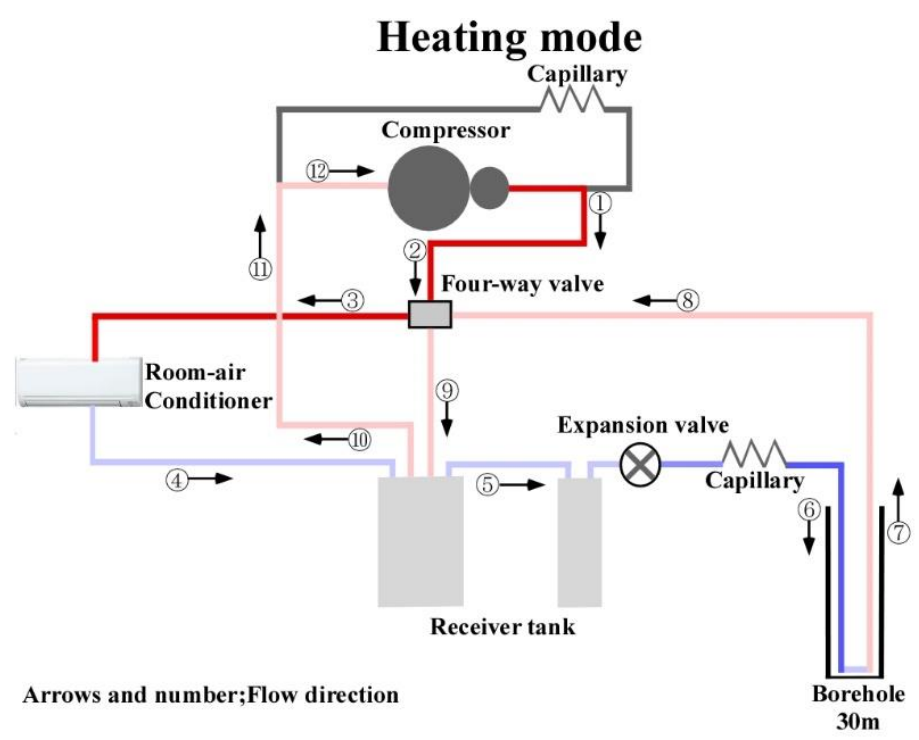

Figure 1 Flow sheet of the direct expansion method GSHP system

Figure 1 shows representatively a schematic diagram of the experimental apparatus. The experiment apparatus was basically composed of a compressor, underground heat exchanger in the borehole, an expansion valve and an air conditioner. The size of a borehole is $105.3 \mathrm{~mm}$ in diameter and $30 \mathrm{~m}$ in depth. In the borehole, heat transfer tube is surrounded by water. The outside of the borehole is covered by silica sand. R410A as a refrigerant and oil were mixed to prevent from burning of compressor. In heating mode, R410A and oil flow from the compressor to the air conditioner, the expansion valve and the borehole, a four-way valve and back to the compressor. In cooling mode, R410A and oil mixture runs from the compressor to the borehole, the expansion valve, the four-way valve and the air conditioner and back to the compressor. Conversion from the cooling mode to the heating mode was conducted by the four-way valve. After air temperature at a room is pre-set at $27^{\circ} \mathrm{C}$ and $20^{\circ} \mathrm{C}$ in cooling and heating mode, respectively, the compressor is operated and the working fluid (R410A and oil) flows through the system. 
Figure 2(a) and (b) show a schematic of the underground heat exchanger. The heat transfer tube was inserted into the casing pipe. The heat transfer tube made of copper is basically $3 / 8$ inch in tube diameter and is separated to five paths with $1 / 4$ inch in tube diameter in the ground heat exchanger. Flow direction of refrigerants go into the five tubes and return from the one tube. At the cooling mode, refrigerants go into vapor in the underground heat exchanger and become liquid with releasing condensation heat. At the heating mode, refrigerants go into liquid in the underground heat exchanger and become vapor with extracting heat.

Figure 3 (a) shows major measuring points of temperature, humidity, and air flow rate at the inlet and outlet at room air conditioner. A platinum resistance thermometer and a thermocouple were used to measure temperatures. The arrow indicates the direction of flow of the air.

Figure 3 (b) shows major measuring points of flow rate and temperature at the outlet at room air conditioner.

Performance of the GSHP system was evaluated by Coefficient of Performance (COP), which is defined as the ratio of heat exchange rate in air conditioner to consumption power of the compressor, namely.

$\mathrm{COP}=\rho \mathrm{Av}\left(\mathrm{h}_{\text {in }}-\mathrm{h}_{\text {out }}\right) / \mathrm{Wp}$

which $\rho$ is density of air, A is duct area, $v$ is wind speed, $h_{\text {in }}$ and $h_{\text {out }}$ is inlet and outlet enthalpy the room air conditioner, $\mathrm{Wp}$ is power consumption of heat pump, respectively.

Experimental conditions described above were arranged in Table 1.

Table 1 Experimental condition

\begin{tabular}{|l|l|}
\hline \multicolumn{2}{|c|}{ Primary side } \\
\hline Depth of borehole & $30 \mathrm{~m}$ \\
\hline Borehole diameter & $100 \mathrm{~A}(105.3 \mathrm{~mm})$ \\
\hline Filed material & Silica sand \\
\hline Refrigerant & R410A $(6.95 \mathrm{~kg}$, Oil $(1 \ell))$ \\
\hline \multicolumn{2}{|c|}{ secondary side } \\
\hline Power of indoor unit & $4.0 \mathrm{~kW}$ \\
\hline Air conditioning area & $38 \mathrm{~m}^{2}$ \\
\hline Pre-set temperature & Heating $\left(20^{\circ} \mathrm{C}\right)$ \\
\cline { 2 - 2 } & Cooling $\left(27^{\circ} \mathrm{C}\right)$ \\
\hline
\end{tabular}

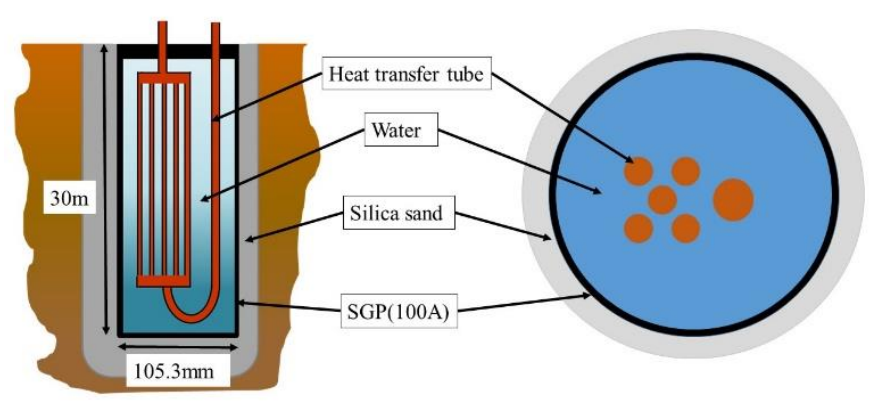

(a) Schematic of underground heat exchanger

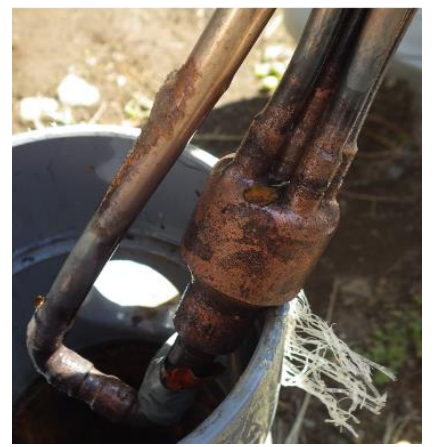

(b) Picture of underground heat exchanger in the bottom section

Figure 2 underground heat exchanger

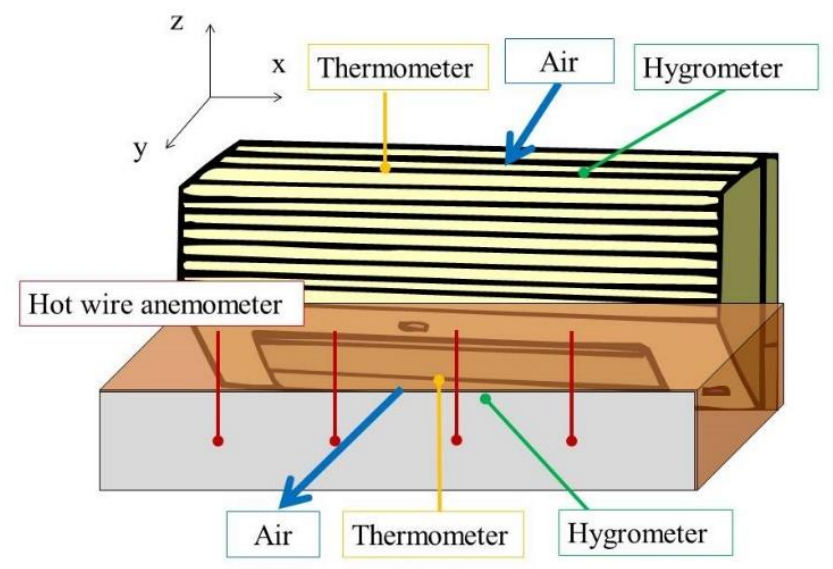

(a) Temperature, humidity, and air flow rate at the inlet and

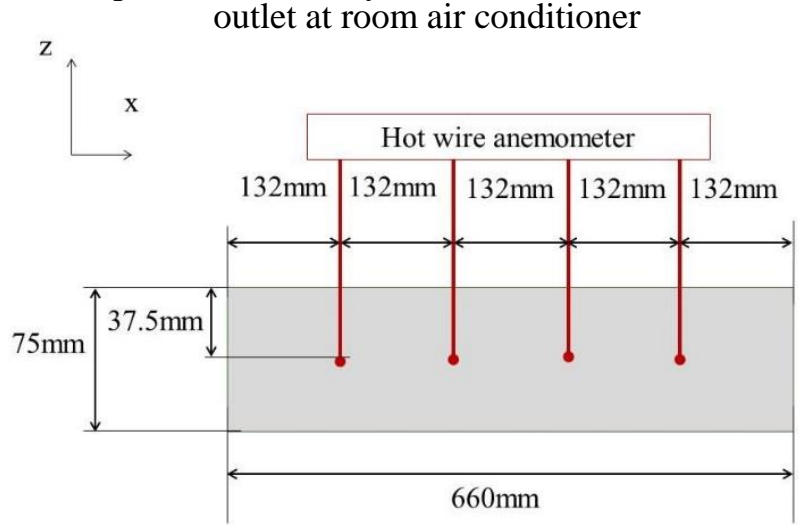

(b) Air flow rate at the outlet at room air conditioner

Figure 3 Major measuring points at room air conditioner

\section{RESULTS AND DISCUSSIONS \\ 4.1 THERMAL RESPONSE TEST}

Table 2 shows the results from thermal response tests conducted in May 10, 2013. The table shows that the thermal conductivity and thermal resistance of the underground were $1.69 \mathrm{~W} / \mathrm{mK}$ and $0.08 \mathrm{mK} / \mathrm{W}$, respectively. Figure 4 shows the distribution of the underground temperature. The underground temperature deeper than $10 \mathrm{~m}$ depth was stable, but that less than $10 \mathrm{~m}$ depth was affected by solar thermal energy. The average of the underground temperature is $18.3^{\circ} \mathrm{C}$ [8]. 
Table 2 Result of the thermal response test

\begin{tabular}{|c|c|}
\hline Depth of borehole & $30 \mathrm{~m}$ \\
\hline Borehole diameter & $100 \mathrm{~A}(105.3 \mathrm{~mm})$ \\
\hline Filed material & Silica Sand \\
\hline Themal conductivity & $1.69 \mathrm{~W} / \mathrm{mK}$ \\
\hline Underground temperature & $18.3^{\circ} \mathrm{C}$ \\
\hline Flow rate & $201 / \mathrm{min}$ \\
\hline Heated power & $1.96 \mathrm{~kW}$ \\
\hline Density & $1.96 \mathrm{~g} / \mathrm{cm}^{3}$ \\
\hline Specific heat capacity & $1.21 \mathrm{~kJ} / \mathrm{kgK}^{-}$ \\
\hline Themal diffusivity & $7.16 \times 10^{-7} \mathrm{~m}^{2} / \mathrm{s}$ \\
\hline Themal resistance & $0.08 \mathrm{mK} / \mathrm{W}$ \\
\hline
\end{tabular}

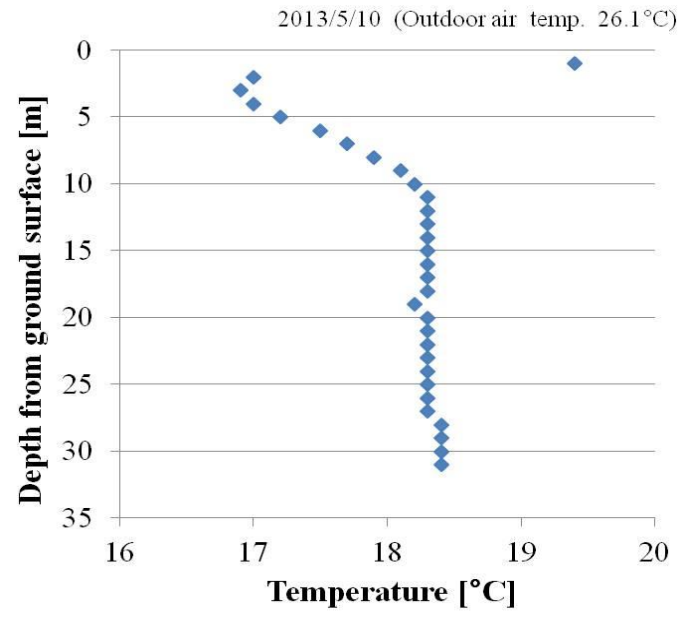

Figure 4 Temperature distribution of the underground

\subsection{COOLING MODE}

Figure 5, 6, 7 and 8 show representative results on pressure and temperature (pre-set temperature $27^{\circ} \mathrm{C}$ ). The experiment was continuously during 48 hours from 10 am on August 4, 2014 to 10 am on August 6, 2014.

Figure 5 shows the change in pressure at four locations in the primary side. The amplitude of pressure change was stable at around $0.1-0.25 \mathrm{MPa}$, but the compressor output pressure, the borehole input, and the output pressure steadily increased after the start of the operation, each increasing by about $0.6 \mathrm{MPa}$ in 48 hours.

Figure 6 shows the temperature change at five locations in the primary side corresponding to the pressure changes. After the start of the operation, the refrigerant temperature at compressor outlet and borehole input temperature increased to about $70^{\circ} \mathrm{C}$, then decreased to about $30^{\circ} \mathrm{C}$, and stabilized with a fluctuation amplitude of $6-7^{\circ} \mathrm{C}$. Then, the temperature suddenly started to fluctuate around $40^{\circ} \mathrm{C}-65^{\circ} \mathrm{C}$ about 24 hours after the start of the operation. This is partly due to the fact that the continuous operation over an extended period of time led the borehole temperature to rise, affecting the heat exchange characteristics underground. It is necessary to understand the refrigerant condition in the primary side to elucidate this phenomenon.

Figure 7 shows the performance evaluation summary. There was not large change in the output power, taking into account the relative enthalpy change between the air output and input, stabilized around $3.5 \mathrm{~kW}$. COP decreased by 1 , accompanying the rise in the borehole temperature starting 24 hours after the start however, the value was still high around 12 . This is because there was a temperature difference high enough, $10{ }^{\circ} \mathrm{C}$ on average, between the borehole input and output. Also, in this experiment we did not observe the issues with direct exemption GSHP such as the resistance of the pipes underground for collecting and radiating heat and the instabilities in the primary refrigerant circulation such as stagnation of lubricant in the lower part. We suppose that this is because the borehole length was shortened to $30 \mathrm{~m}$, improving the shape of the underground heat exchanger into that with multiple short pipes. In indirect method, the output power from the underground per $1 \mathrm{~m}$ depth is of borehole 30-40 W/m in indirect method [3], while in the direct expansion method it is twice times as large, $116 \mathrm{~W} / \mathrm{m}$ in cooling mode.

Figure 8 shows that, we compered released heat with changing water temperature in borehole at $10 \mathrm{~m}, 20 \mathrm{~m}$ and $30 \mathrm{~m}$ to research a characteristic of released heat to underground. If it is focused on temperature changing of borehole depth, it will be found that borehole temperature at $10 \mathrm{~m}$ and $20 \mathrm{~m}$ rises steeply with starting operation and the released heat raises the underground temperature of $20^{\circ} \mathrm{C}$, on the other hand borehole temperature at $30 \mathrm{~m}$ has constant value. At the cooling mode, refrigerants go into vapor in the heat transfer tube and become liquid with releasing condensation heat. We can't confirm a state of refrigerants visually, but it infer from the changing temperature that Finish condensation process already, be able to exchange heat at $20 \mathrm{~m}$ to $30 \mathrm{~m}$. However liquid refrigerants release only change of sensible heat at $30 \mathrm{~m}$ and amount of heat exchange didn't have much.

\subsection{HEATING MODE}

Figure 9, 10, 11 and 12 show representative results on pressure and temperature (pre-set temperature $20^{\circ} \mathrm{C}$ ). The experiment was continuously during 48 hours from 14 pm on January 6, 2016 to 14 am on January 8, 2016.

Figure 9 shows the change in pressure at four locations in the primary system. The compressor output pressure increased to 2.6 $\mathrm{MPa}$ after the start of the operation and fluctuated between 1.8 and 2.3 MPa thereafter.

Figure 10 shows the temperature change at the five locations in the primary side corresponding to the pressure changes. After the start of the operation, the refrigerant temperature at compressor outlet fluctuated around $30^{\circ} \mathrm{C}-50^{\circ} \mathrm{C}$, incurring a load on the compressor.

Figure 11 shows the performance evaluation summary. On average over the operation period, $\mathrm{COP} \fallingdotseq 4.2$, output power 2.6 $\mathrm{kW}$, and consumed electric energy $0.6 \mathrm{~kW}$. The reason for the lower COP than in the refrigerating operation is likely that the underground heat exchanger acts as a vaporizer, and the liquid refrigerant became a resistance in the five outgoing thin pipes, which incurred a load on the compressor and increased the consumed power. It is necessary that reconsidering the shape of underground heat exchanger in the future. In indirect method, the output power from the underground per $1 \mathrm{~m}$ depth is of borehole $30-40 \mathrm{~W} / \mathrm{m}$ in indirect method [3], while in the direct expansion method it is three times as large, $86 \mathrm{~W} / \mathrm{m}$, in a heating mode. 


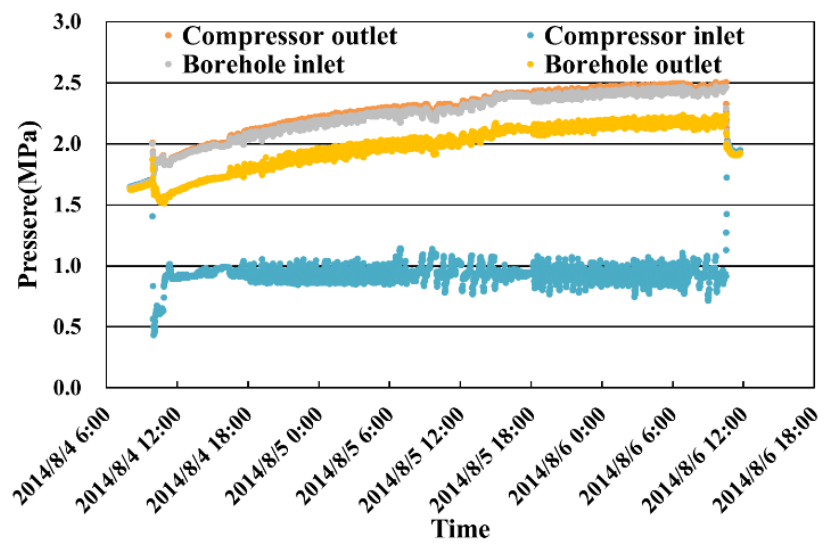

Figure 5 Pressure changes at various points in cooling mode

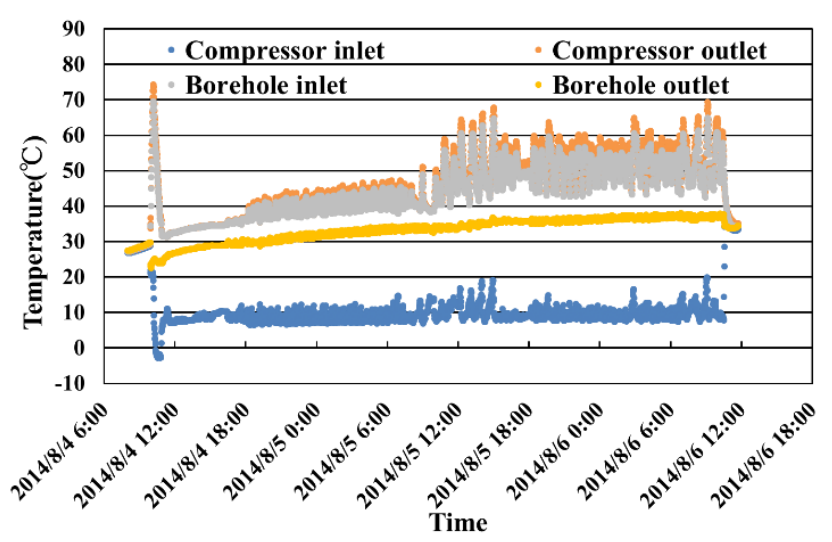

Figure 6 Temperature changes at various points in cooling mode

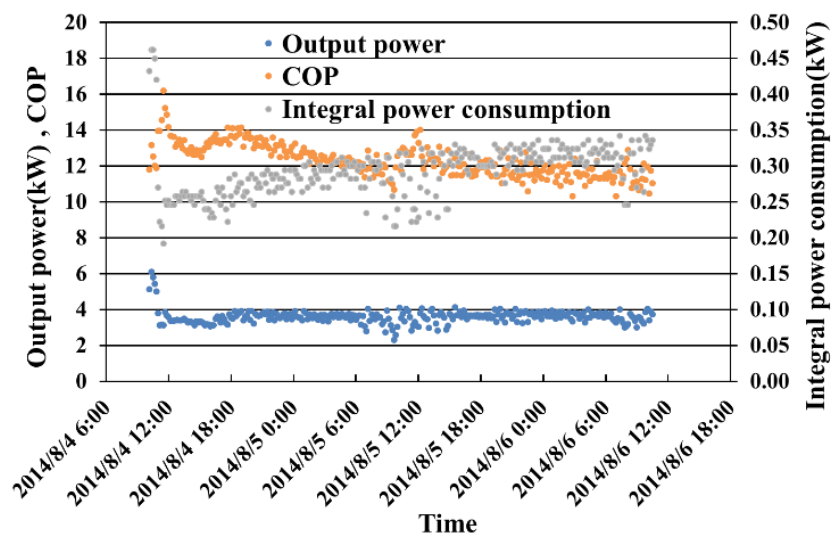

Figure 7 Coefficient of performance and amounts of heat transferred in cooling mode

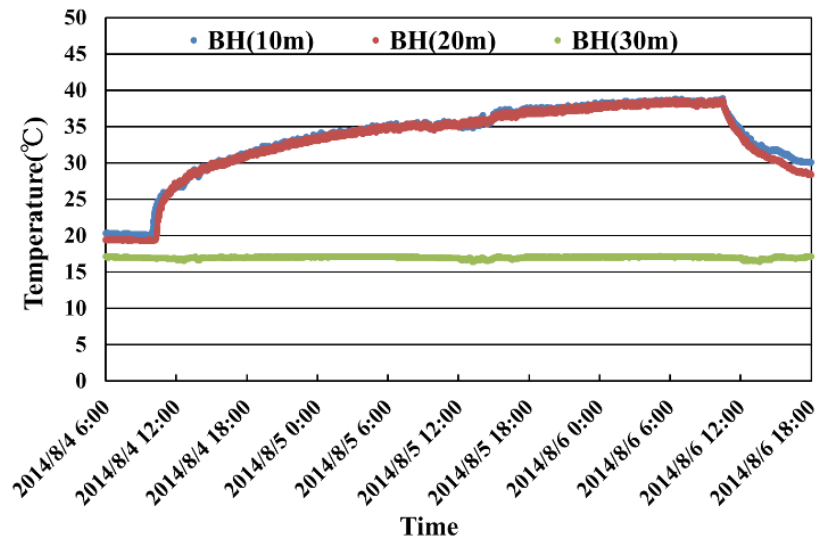

Figure 8 Borehole water temperature in cooling mode

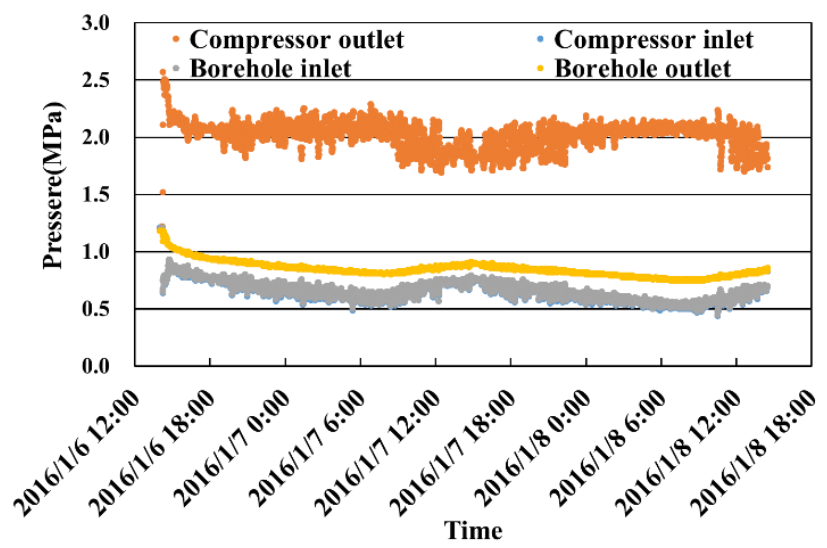

Figure 9 Pressure changes at various points in heating mode

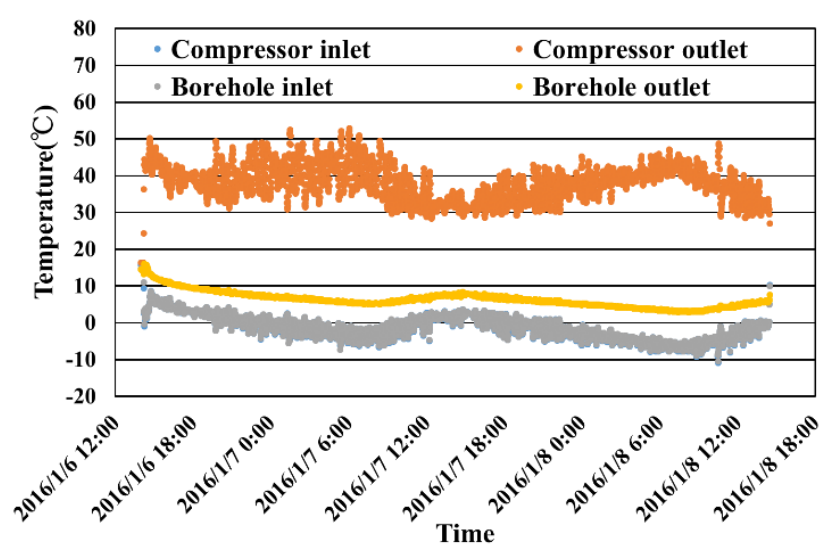

Figure 10 Temperature changes at various points in heating mode 


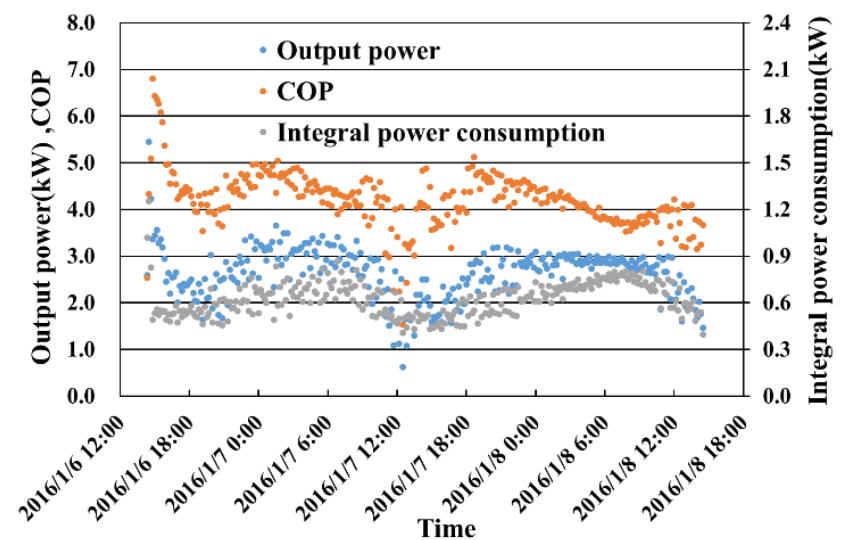

Figure 11 Coefficient of performance and amounts of heat transferred in heating mode

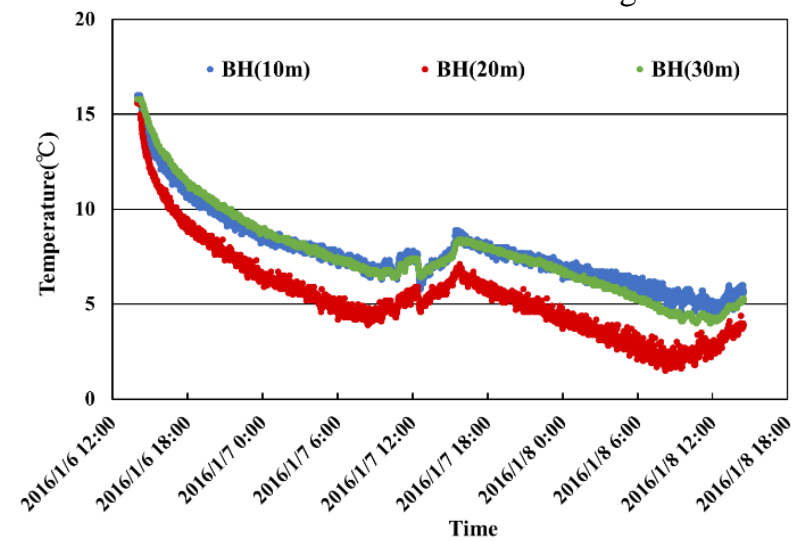

Figure 12 Borehole water temperature in heating mode

Figure 12 shows that we compered extracted heat with changing water temperature in borehole at $10 \mathrm{~m}, 20 \mathrm{~m}$ and $30 \mathrm{~m}$ to research a characteristic of extracted heat from underground. If it is focused on temperature changing of borehole depth, it will be found that the borehole temperature at $10 \mathrm{~m}, 20 \mathrm{~m}$ and $30 \mathrm{~m}$ in each point decreases rapidly with starting operation and the extracted heat lowers the underground temperature of $15^{\circ} \mathrm{C}$. Moreover, temperature decreased about amount of $10^{\circ} \mathrm{C}$ at $30 \mathrm{~m}$ though not change in cooling mode. Temperature changes the whole borehole because of not finish vaporization process yet.

The first law of thermodynamics is defined as $\mathrm{Q}_{\text {out }}=\mathrm{Q}_{\text {in }}+\mathrm{W}$. However, the law did not have equality in this study. It was because the value of $\mathrm{Q}_{\text {out }}$ and $\mathrm{W}$ were lower than ideal condition. $\mathrm{Q}_{\text {out }}$ became lower because the borehole temperature changes the whole borehole because of not finish vaporization process yet in heating mode. The extracted heat from underground was not enough. W became lower because the pipe friction of the refrigerant became larger when the liquid refrigerant passed through the five thin pipes. It increased the consumed power of compressor in heating mode.

\section{CONCLUSIONS}

The following knowledge was obtained from 48 hours of continuous operation of GSHP using direct expansion method with borehole of depth $30 \mathrm{~m}$ each.

1) We did not observe the issues such as the resistance of the pipes underground for collecting and radiating heat and the instabilities in the primary refrigerant circulation such as stagnation of lubricant in the lower part. Therefore, operating of this GSHP using direct expansion method is possible.

2) The COP value determined from the heat in the indoor equipment and the consumed power by the heat pump was COP $\fallingdotseq 12.3$ in a cooling mode with the secondary pre-set temperature $27{ }^{\circ} \mathrm{C}$, and $\mathrm{COP} \fallingdotseq 4.2$ in a heating mode with the pre-set temperature $20^{\circ} \mathrm{C}$.

3) In indirect method, the output power from the underground per $1 \mathrm{~m}$ depth is of borehole $30-40 \mathrm{~W} / \mathrm{m}$ in indirect method, while in the direct expansion method it is three times as large, $116 \mathrm{~W} / \mathrm{m}$, in a cooling mode, and about twice as high, 86 $\mathrm{W} / \mathrm{m}$ in heating mode, collected from the earth. Therefore, our system is one with high efficiency.

4) In the cooling mode, it was able to exchange enough heat with underground using one borehole of $30 \mathrm{~m}$ depth because finish condensation process already, be able to exchange heat at $20 \mathrm{~m}$ to $30 \mathrm{~m}$. In the heating mode, however, it was not enough extracted heat from underground. The reason that temperature changes the whole borehole because of not finish vaporization process yet.

A part of this work was supported by JKA and its promotion funds from KEIRIN RACE (27-134).

\section{REFERENCES}

[1]Y. Kaya (edited), (2002),'Encyclopedia on New Energy", Kogyo Chosakai Publishing Co. Ltd.

[2]K. Nagano, (2012) "Current State of Ground Source Heat Pump System”, Journal of Japanese Association of Groundwater Hydrogy, Vol. 54, No.2, pp.95-105.

[3]Hokkaido University, 2007, Ground Source Heat Pump System, Ohmsha, Tokyo, Japan.

[4]S. Ishiguro, T. Takeda, K. Ichimiya, and S. Funatani (2013): "Experiment on Ground Source Heat Pump Based on Direct Expansion", Proc. of the 24th Int. Symposium on Transport Phenomena, pp704-708

[5]D. Yokoyama, T. Takeda, S. Funatani, K. Ichimiya, S. Ishiguro (2014): "Demonstration Experiment of Ground Source Heat Pump System Using Direct Expansion Method", Proc. of the 25th Int. Symposium on Transport Phenomena, Paper No.26.

[6]T. Takeda, D. Yokoyama, A. Ohashi, S. Ishiguro, S. Funatani , K. Ichimiya, (2014): "Experimental Study on Ground Source Heat Pumps that Use the Direct Expansion Method", Proc. of the 15th Int. Heat Transfer Conference, Paper No.IHTC15-8940.

[7]A. Watanabe, T. Takeda, S. Funatani, K. Ichimiya, S. Ishiguro (2015): "Performance of ground source heat pump that use direct expansion method - Characteristics of extracting and releasing heat to the ground - " Proc. of the 26th Int. Symposium on Transport Phenomena, Paper No.75

[8]H. Fujii, Y, Komaba, (2011): “ The Principle and Analyzing Method of Thermal Response Test - Examples -“, Journal of Japanese Association of Groundwater Hydrology, Vol.53, No.4, pp.391-400. 